\title{
Trauma resuscitation requiring massive transfusion: a descriptive analysis of the role of ratio and time
}

\author{
Ruben Peralta', Adarsh Vijay ${ }^{1}$, Ayman El-Menyar ${ }^{2,3^{*}}$, Rafael Consunji ${ }^{1}$, Husham Abdelrahman ${ }^{1}$, Ashok Parchani ${ }^{1}$, \\ Ibrahim Afifi ${ }^{1}$, Ahmad Zarour ${ }^{1,3}$, Hassan Al-Thani ${ }^{1}$ and Rifat Latifi ${ }^{1,4}$
}

\begin{abstract}
Objective: We aimed to evaluate whether early administration of high plasma to red blood cells ratios influences outcomes in injured patients who received massive transfusion protocol (MTP).

Methods: A retrospective analysis was conducted at the only level 1 national trauma center in Qatar for all adult patients $(\geq 18$ years old) who received MTP ( $\geq 10$ units) of packed red blood cell (PRBC) during the initial $24 \mathrm{~h}$ post traumatic injury. Data were analyzed with respect to FFB:PRBC ratio [(high $\geq 1: 1.5)$ (HMTP) vs. (low $<1: 1.5)$ (LMTP)] given at the first $4 \mathrm{~h}$ post-injury and also between ( $>4$ and $24 \mathrm{~h}$ ). Mortality, multiorgan failure (MOF) and infectious complications were studied as well.

Results: During the study period, a total of 4864 trauma patients were admitted to the hospital, $1.6 \%(n=77)$ of them met the inclusion criteria. Both groups were comparable with respect to initial $\mathrm{pH}$, international normalized ratio, injury severity score, revised trauma score and development of infectious complications. However, HMTP was associated with lower crude mortality ( 41.9 vs. $78.3 \%, p=0.001)$ and lower rate of MOF (48.4 vs. $87.0 \%, p=0.001)$. The number of deaths was 3 times higher in LMTP in comparison to HMTP within the first 30 days (36 vs. 13 cases). The majority of deaths occurred within the first $24 \mathrm{~h}$ ( $80.5 \%$ in LMTP and $69 \%$ in HMTP) and particularly within the first 6 h ( 55 vs. $46 \%)$.
\end{abstract}

Conclusions: Aggressive attainment of high FFP/PRBC ratios as early as $4 \mathrm{~h}$ post-injury can substantially improve outcomes in trauma patients.

Keywords: Trauma, Transfusion ratio, Massive transfusion protocol, Outcome

\section{Background}

In severe trauma patients, exsanguinating hemorrhage is the most common cause of early death, which occurs within the first few hours of hospital admission $[1,2]$. Up to $30 \%$ of severely injured patients are coagulopathic upon arrival to the emergency department [3]. Moreover, the coagulopathy status developed early post traumatic injury invariably complicates the massive blood transfusion and damage control resuscitation pattern and outcome. Prior reports of the military and civilian experience that

\footnotetext{
* Correspondence: traumaresearch@hamad.qa

${ }^{2}$ Clinical Research, Trauma Surgery Section, Hamad General Hospital, HMC PO Box 3050, Doha, Qatar

${ }^{3}$ Clinical Medicine, Weill Cornell Medical College, Doha, Qatar

Full list of author information is available at the end of the article
}

advocated the use of higher ratios of fresh frozen plasma (FFP) to packed red blood cells (PRBCs) showed an improvement in survival of trauma patients $[4,5]$. These studies have addressed the implications of early aggressive hemostatic resuscitation to control coagulopathy, which potentially reduces the mortality rate. However, some investigators suggested that transfusion of inappropriate volumes of plasma might result in a higher incidence of infection or transfusion-associated acute lung injury [6-8]. According to the current guidelines of hemostatic resuscitation, severe trauma patients should be supplemented with a considerable amount of blood products (PRBC, FFP and platelet) in an early and continuous manner [9]. However, there is no consensus on the optimal ratio of FFP to PRBC for trauma patients requiring massive transfusion protocol 
(MTP). Borgman et al. [4] proposed a predictive model of MTP in severe trauma patients. The authors suggested that a high ratio (FFP: RBC) ( $\geq 15$ TASH score) was an independent predictor of survival; whereas, the low ratio $(<15$ TASH score) was correlated well with higher complication rates.

There is still ongoing debate to define the most appropriate time and ratio of MTP that should be given to patients undergoing hemostatic resuscitation. Specifically, the appropriate timing and resuscitation ratio during the early hours of severe trauma remain unclear. Herein, we aimed to evaluate whether early administration of high plasma ratios to RBC influences outcomes in trauma patients receiving massive blood transfusion.

\section{Methods}

We conducted a retrospective analysis of the prospectively collected data of all adult trauma ( $\geq 18$ years old) patients who received MTP. The study was conducted at the Hamad Trauma Center which is the only level 1 national trauma referral center in Qatar from January 2010 to December 2012. Blood bank records were used to identify patients who received more than 6 units PRBC. The records were then screened for subset of patients who received more than 10 units PRBC in the first $24 \mathrm{~h}$. The medical records of patients were obtained to evaluate the ratio based on actual blood products transfused, the actual time of transfusion along with the details of other comorbid conditions, complications and outcome. All patients who died on arrival were excluded. We defined MTP as the infusion of $\geq 10$ units of PRBC over the initial $24 \mathrm{~h}$ post-injury [10]. Injury Severity Scores (ISS) and Revised Trauma Scores (RTS) were collected from the hospital trauma database for all cases. Based on FFP: PRBC ratio at $4 \mathrm{~h}$ post-injury; patients were categorized into two groups i.e. high MTP (HMTP) who received FFP: PRBC ratio $\geq 1: 1.5$ and low MTP (LMTP) who received a FFP: PRBC ratio of $<1: 1.5$. The ratio of FFP: PRBC administered was calculated for each patient at $4 \mathrm{~h}$ and the ratios were also calculated based on the blood products given from 4 to $24 \mathrm{~h}$ post injury in the same cohort to look for the effect of timing and transfusion ratios. Our analysis is based on the actual transfusion of blood products and MTP of our institution including 6 units of RBC, 6 units of FFP, and 6 units of platelets. Two units of uncross-matched blood were available to each patient without delay. All patients were followed-up until hospital discharge or death. The outcomes measures included mortality, $1^{\text {st }}$ MTP International Normalized Ratio (INR), multiorgan failure (MOF) and infectious complications.

We intended to analyze the outcomes in relation to the transfusion ratios calculated initially at $4 \mathrm{~h}$ and at $4-24 \mathrm{~h}$.
In particular, we looked at the effect of early $(<4 \mathrm{~h}) \mathrm{MTP}$ ratios on the final outcome.

\section{Definitions}

The diagnosis of MOF was based on a maximum Marshall Multiple Organ Dysfunction score $>5$. Ventilator associated pneumonia (VAP) diagnosis was based on the quantitative culture threshold of $\geq 10^{4} \mathrm{CFU} / \mathrm{mL}$ for broncho-alveolar lavage [11]. Blood stream infection (BSI) is a positive blood culture that not necessarily related to an indwelling central venous catheter. Whereas, line related infection was defined as catheter-related blood stream infections (CRBSI) which required positive peripheral cultures with the identical organism obtained from either a positive semi-quantitative culture ( $\geq 15 \mathrm{CFU} /$ segment), or positive quantitative culture $\left(\geq 10^{3} \mathrm{CFU} /\right.$ segment) from a catheter segment specimen. Urinary tract infection (UTI) was confirmed if the urine specimen revealed $\geq 10^{5}$ organisms $/ \mathrm{ml}$. This study was approved by the medical research center at Hamad Medical Corporation, Qatar (IRB \# 11153/11).

\section{Statistical analysis}

Data were presented as proportions, mean \pm standard deviation (SD) or median as appropriate. Baseline demographic characteristics, clinical presentation, and outcomes were compared according to FFP: PRBC ratio at 4 h (HMTP vs. LMTP). Pearson chi-square $\left(X^{2}\right)$ test was used for categorical variables and student- $t$ test for continuous variables. The Fisher's exact test was used, if the expected cell frequencies were below 5 . A significant difference was considered when the 2-tailed $p$ value was less than 0.05. Data analysis was carried out using the Statistical Package for Social Sciences version 18 (SPSS Inc. USA).

\section{Results}

During the 3- year study period, there were 4864 trauma admissions, of which 100 patients received massive blood transfusion. Finally, the study included 77 (1.6\%) cases in which ratios were attainable and the remaining 23 cases were excluded as they did not receive FFP within the first $4 \mathrm{~h}$ post-injury and so no ratio could be calculated. The mean age of patients was $33.7 \pm 14$ years and the majority of them were males (91\%). Blunt trauma accounted for most of cases $(88.3 \%)$. The median ISS, GCS and RTS were 29 (8-75), 4.4 \pm 3.8 , and 4 (1.2-7.8), respectively (Table 1). Lung contusion (62.3\%), head injury (50\%), pelvic $(46.7 \%)$ and rib fracture $(35.5 \%)$ were the most commonly associated injuries. The most frequent used operative interventions included exploratory laparatomy (66.2\%), Thoracotomy (24.7\%), repair of major vessels (22\%) and angioembolization (13\%). Among patients who underwent emergency operative interventions, $39 \%$ 
Table 1 Demographics and presentation of study cohort $(n=77)$

\begin{tabular}{|c|c|c|c|}
\hline \multicolumn{2}{|l|}{ Variable } & \multicolumn{2}{|l|}{ Variable } \\
\hline Age (mean $\pm S D$; years) & $33.7 \pm 14$ & Injured body region & \\
\hline Males & $69(90.8 \%)$ & Head & $32(50 \%)$ \\
\hline Blunt trauma & $68(88.3 \%)$ & Lung contusion & $48(62.3)$ \\
\hline Mechanism of injury & & Rib fracture & $27(35.5 \%)$ \\
\hline Traffic Pedestrian & $22(28.6 \%)$ & Pelvic fracture & $35(46.7 \%)$ \\
\hline Traffic Driver & $20(26 \%)$ & Long bone fracture & $24(32.0 \%)$ \\
\hline Traffic Passenger & $12(15.6 \%)$ & Spleen & $21(27.3 \%)$ \\
\hline Fall From Height & $10(13 \%)$ & Liver & $25(32.5 \%)$ \\
\hline fall of heavy object & $5(6.5 \%)$ & Bowel & $15(19.5 \%)$ \\
\hline crush injury & $1(1.3 \%)$ & Pancreas & $9(11.7 \%)$ \\
\hline Gunshot & $1(1.3 \%)$ & Cardiac & $4(5.2 \%)$ \\
\hline Stab & $5(6.5 \%)$ & Operative interventions & \\
\hline SBP $(\mathrm{mmHg})$ & $85.2 \pm 35.5$ & Exploratory Laparotomy & $51(66.2 \%)$ \\
\hline Heart rate (b/min) & $119.3 \pm 27.6$ & Thoracotomy & $19(24.7 \%)$ \\
\hline Temperature in ED $\left({ }^{\circ} \mathrm{C}\right)$ & $36.1 \pm 0.66$ & Repair of major vessels & $17(22.1 \%)$ \\
\hline FAST positive & $41(53.2 \%)$ & Chest tube insertion & 7 (9.1%) \\
\hline Laboratory Findings & & Craniotomy & $1(1.3 \%)$ \\
\hline Initial Hemoglobin (g/dL) & $10.3 \pm 2.6$ & External fixation & $6(7.8 \%)$ \\
\hline Initial Platelets $\left(\times 10^{9} / \mathrm{L}\right)$ & $187.7 \pm 69.8$ & ORIF & $1(1.3 \%)$ \\
\hline Initial INR & $1.6 \pm 1.2$ & Mangled extremity amputation & $3(3.9 \%)$ \\
\hline Initial APTT (median) & $30.3(22-149)$ & Successful Angioembolization & $10(13 \%)$ \\
\hline Initial Fibrinogen (g/L) & $0.96 \pm 0.58$ & Intra-operative status & \\
\hline Initial pH & $7.1 \pm 0.2$ & Stable + damage control & 30 (39 \%) \\
\hline Initial HCO3 (mmol/L) & $15.6 \pm 3.8$ & Unstable + damage control & $24(31.2 \%)$ \\
\hline Saline & $3739 \pm 1411$ & Stable + procedure completed & $8(10.4 \%)$ \\
\hline Ringer Lactate (mmol/L) & $1300 \pm 958$ & unstable + procedure completed & $1(1.3 \%)$ \\
\hline Blood products transfused $<4 \mathrm{~h}$ & & Intra-operative mortality & $13(20.6 \%)$ \\
\hline PRBC & $10.9 \pm 4.9[10(2-23)]$ & ICU LOS & $3(1-45)$ \\
\hline FFP & $6.5 \pm 3.8[6(1-21)]$ & Overall Hospital LOS (days) & $1.5(1-112)$ \\
\hline Platelet & $6.4 \pm 3.4[6(1-22)]$ & Hospital LOS & $28(8-112)$ \\
\hline Severity Scores & & Multi Organ Failure & $49(63.6 \%)$ \\
\hline Injury Severity Score & $29(8-75)$ & Overall mortality & $55(71.4 \%)$ \\
\hline Revised Trauma Score & $4(1.2-7.8)$ & & \\
\hline Glasgow Coma Score & $3(3-15)$ & & \\
\hline
\end{tabular}

FFP Fresh frozen plasma, PRBC packed red-blood-cells, ICU Intensive Care Unit, LOS length of stay, FAST Focused Assisted Sonography for Trauma, INR international normalized ratio, APTT Activated Partial Thromboplastin Time, SBP Systolic Blood Pressure, ORIF Open reduction internal fixation

bold means heading variable non-bold means subheadings of the main variable

had damage control surgery. The intra-operative mortality was $17 \%$. Focused assessment with sonography for trauma (FAST) was positive in more than half of the cases $(53 \%)$. The median intensive care unit (ICU) stay was 3 (1-45) days, the overall hospital length of stay was 2 (1-112) days and the hospital length of stay for patients who survived was $28(8-112)$. Transport time to the trauma center was $64 \pm 32.3 \mathrm{~min}$. According to our institutional policy, blood transfusion begins only after arrival to the hospital, whereas prehospital crystalloid (normal saline) administration is initiated by EMS.

Table 2 shows the clinical presentation and outcome of patients based on FFP: PRBC ratio (HMTP and LMTP) within the first $4 \mathrm{~h}$. The mean age of the LMTP group was higher $(37.6 \pm 16.5$ vs. $29.7 \pm 9.5 ; P=0.03)$ in comparison to HMTP group. However, both the HMTP $(\mathrm{n}=31)$ and LMTP $(n=46)$ groups were comparable with respect to gender, mechanism of injury, prehospital intubation, 
Table 2 Clinical presentation and complications based on high and low transfusion ratios within the first $4 \mathrm{~h}$ post-injury

\begin{tabular}{|c|c|c|c|}
\hline & $\begin{array}{l}\text { HMTP } \\
(n=31)\end{array}$ & $\begin{array}{l}\text { LMTP } \\
(n=46)\end{array}$ & $P$ value \\
\hline Age (mean $\pm S D)$ & $29.7 \pm 9.5$ & $37.6 \pm 16.5$ & 0.03 \\
\hline Blunt injury (\%) & 87.1 & 89.1 & 0.53 \\
\hline Penetrating injury (\%) & 12.9 & 10.9 & \\
\hline Saline (Prehospital) & $1193 \pm 666$ & $1197 \pm 737$ & 0.97 \\
\hline Transport Time (min.) & $64.4 \pm 29.8$ & $63.7 \pm 34.3$ & 0.93 \\
\hline \multicolumn{4}{|l|}{ Prehospital interventions } \\
\hline Intubation & $36 \%$ & $41 \%$ & 0.60 \\
\hline Thoracostomy & $3 \%$ & $9 \%$ & 0.32 \\
\hline \multicolumn{4}{|l|}{ Laboratory findings } \\
\hline Initial Hemoglobin (mean \pm SD) & $10.6 \pm 3$ & $10 \pm 2.3$ & 0.37 \\
\hline Initial INR & $1.3(1-10)$ & $1.3(1-3)$ & 0.09 \\
\hline Initial pH & $7.2 \pm 0.14$ & $7.1 \pm 0.2$ & 0.09 \\
\hline${ }^{*} 1^{\text {ST }}$ MTP INR & $1.35(1-2)$ & $1.7(1-12)$ & 0.09 \\
\hline $1^{\text {st }} \mathrm{MTP} \mathrm{pH}$ & $7.2 \pm 0.16$ & $7.1 \pm 0.23$ & 0.04 \\
\hline $2^{\text {nd }}$ MTP INR & $1.1(1-3)$ & $1.5(1-3)$ & 0.03 \\
\hline $2^{\text {nd }} M T P p H$ & $7.3 \pm 0.1$ & $7.2 \pm 0.2$ & 0.04 \\
\hline 3rd MTP INR & $1.1(1-2)$ & $1.2(1-10)$ & 0.17 \\
\hline $3^{\text {rd }} \mathrm{MTP} \mathrm{pH}$ & $7.2 \pm 0.18$ & $7.2 \pm 0.2$ & 0.55 \\
\hline Saline & $3456 \pm 1591$ & $3929 \pm 1258$ & 0.15 \\
\hline Ringer Lactate & $883 \pm 431$ & $1550 \pm 1099$ & 0.01 \\
\hline Saline + Ringer lactate & $3883 \pm 1580$ & $4771 \pm 1466$ & 0.01 \\
\hline Cryoprecipitate & $9.5 \pm 0.7$ & $8.4 \pm 3.5$ & 0.70 \\
\hline Calcium Gluconate/Chloride & $1933 \pm 1334$ & $2250 \pm 1674$ & 0.54 \\
\hline Sodium Bicardonate & $92.9 \pm 73$ & $152.3 \pm 96$ & 0.05 \\
\hline Fibrinogen & $2800 \pm 1095$ & $3000 \pm 1341$ & 0.77 \\
\hline Factor VII & $5.2 \pm 2.4$ & $3.8 \pm 1.3$ & 0.19 \\
\hline \multicolumn{4}{|l|}{ Injuries } \\
\hline Head injury & 52 & 48.6 & 0.80 \\
\hline Lung contusion & 68 & 59 & 0.42 \\
\hline Rib fracture & 47 & 28 & 0.10 \\
\hline Pelvic fracture & 52 & 43 & 0.47 \\
\hline Long bone fracture & 45 & 23 & 0.04 \\
\hline Spleen & 19 & 33 & 0.2 \\
\hline Liver & 26 & 37 & 0.3 \\
\hline Cardiac & 0 & 9 & 0.09 \\
\hline Injury Severity Score & $29.4 \pm 11.6$ & $32.5 \pm 10.7$ & 0.24 \\
\hline Revised Trauma Score & $5.2 \pm 2.3$ & $5.2 \pm 2.02$ & 0.97 \\
\hline Glasgow Coma Score & $8.5 \pm 5$ & $8 \pm 5.1$ & 0.72 \\
\hline Hyperkalemia (\%) & 17.2 & 29.3 & 0.19 \\
\hline Hypomagnesemia (\%) & 68.2 & 61 & 0.42 \\
\hline Hypocalcemia (\%) & 93 & 82 & 0.17 \\
\hline
\end{tabular}

Table 2 Clinical presentation and complications based on high and low transfusion ratios within the first $4 \mathrm{~h}$ post-injury (Continued)

\begin{tabular}{llll}
\hline Complications & & & \\
Ventilator-associated Pneumonia (\%) & 32.3 & 14 & 0.05 \\
Wound infection (\%) & 32.3 & 18.6 & 0.14 \\
Bloodstream Infection (\%) & 6.5 & 11.6 & 0.37 \\
CRBSI (\%) & 3.2 & 7 & 0.44 \\
Urinary tract infections (\%) & 3.2 & 4.7 & 0.62 \\
ACS (\%) & 6.5 & 2.2 & 0.35
\end{tabular}

HMTP high transfusion ratios, LMTP low transfusion ratios, INR, international normalized ratio, ACS abdominal compartment syndrome, CRBSI Catheter related Blood Stream Infection, MTP massive transfusion protocol

thoracotomy, volume of normal saline administration, initial hemoglobin reading, INR, arterial $\mathrm{pH}$ and severity of injury (ISS \& RTS). The incidence of hyperkalemia, hypomagnesemia and hypocalcemia were also comparable in the two groups. The mean arterial $\mathrm{pH}$ was higher among HMTP group post 1st MTP $(7.2 \pm 0.16$ vs. $7.1 \pm 0.23 ; P=0.04)$ and 2 nd MTP $(7.3 \pm 0.1$ vs. $7.2 \pm 0.2$; $P=0.04)$ as compared to LMTP group. HMTP patients had better mean INR values after the 2nd MTP shipment (1.1 (1-3) vs. 1.5(1-3); $p=0.03)$ than LMTP. Significantly greater amount of Ringer lactate $(1550 \pm 1099 v s$. $883 \pm 431 ; p=0.01)$ and combination of saline and Ringer lactate $(4771 \pm 1466$ vs. $3883 \pm 1580 ; P=0.01)$ were transfused to patients with LMTP.

Though, the frequency of VAP, wound infection and abdominal compartment syndrome were higher in the HMTP group, these trends did not reach statistical significance. However, BSI and UTI were non-significantly higher in LMTP group (Fig. 1).

The overall mortality was $63.6 \%$ (Table 3). Patients who died mainly had lung contusion (42.9\%), head injury (29.9\%), pelvic fracture (28.6\%), liver injury $(24.7 \%)$ and rib fractures (23.4\%). Moreover, significant number of patients in HMTP group who died had

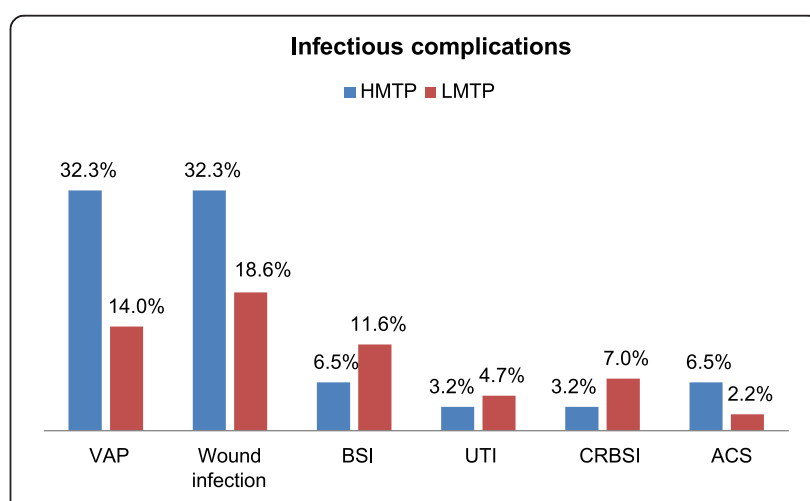

Fig. 1 Distribution of infectious complications according to FFP: PRBC ratios 
Table 3 Outcome based on transfusion ratios

\begin{tabular}{|c|c|c|c|}
\hline & $\operatorname{HMTP}(n=31)$ & $\operatorname{LMTP}(n=46)$ & $P$ value \\
\hline \multicolumn{4}{|c|}{ Mortality by associated injuries (ratios at $<4 h$ ) } \\
\hline Head injury & 88.9 & 55.6 & 0.07 \\
\hline Lung contusion & 69.2 & 66.7 & 0.86 \\
\hline Rib fracture & 66.7 & 27.8 & 0.01 \\
\hline Pelvic fracture & 53.8 & 44 & 0.55 \\
\hline Long bone fracture & 30.8 & 23.5 & 0.61 \\
\hline Spleen & 15.4 & 27.8 & 0.37 \\
\hline Liver & 30.8 & 41.7 & 0.48 \\
\hline Cardiac & 0.0 & 8.3 & 0.28 \\
\hline \multicolumn{4}{|c|}{ Outcomes* based on MTP ratios calculated at $<4 \mathrm{~h}$} \\
\hline Multi Organ Failure (\%) & 48.4 & 87 & 0.001 \\
\hline Mortality (\%) & 41.9 & 78.3 & 0.001 \\
\hline \multicolumn{4}{|c|}{ Outcomes* based on MTP ratios calculated at 4-24 h } \\
\hline Multiorgan failure (\%) & 58.3 & 72.7 & 0.29 \\
\hline Mortality (\%) & 46.7 & 63.6 & 0.24 \\
\hline
\end{tabular}

*It represents the overall outcome (MOF and mortality) and its correlation with the transfusion ratios calculated initially at $4 \mathrm{~h}$ and at 4-24 $\mathrm{h}$

more rib fractures $(66.7 \%$ vs. $27.8 \% ; P=0.01)$ than LMTP group. A non-significantly higher proportion of patients in LMTP group died within $6 \mathrm{~h}$ post-injury in comparison to HMTP. During the early period of resuscitation $(<4 \mathrm{~h})$, the incidence of MOF (48.4\% vs. $87.0 \%, p=0.001)$ and crude mortality ( $41.9 \% v s .78 .3 \%, p=0.001)$ were significantly lower in HMTP compared to LMTP group. However, in the later period (4-24 h) MOF and mortality were comparable among the two groups (Fig. 2).

Figure 3 demonstrates the time to all-cause mortality in those who received LMTP vs. HMPT $(<4 \mathrm{~h})$. The number of deaths was 3 times higher in LMTP in comparison to HMTP within the first 30 days (36 vs. 13 cases). The vast majority of deaths occurred within the first $24 \mathrm{~h}(80.5 \%$ in LMTP and $69 \%$ in HMTP) and particularly within the first $6 \mathrm{~h}$ ( $55 \% v s .46 \%)$.

\section{Discussion}

The present study evaluates the implication of FFP to PRBC ratio and its appropriate timing in trauma patients who required MTP. Our findings support the survival advantage of attaining high FFP to PRBC ratio for trauma patients who are identified early (within the first $4 \mathrm{~h}$ postinjury). Historically, Kashuk et al. [12] suggested a 'bloody vicious cycle' in which hemorrhage, cellular shock and tissue injury contributed to the formation of the lethal triad of coagulopathy, hypothermia, and acidosis. About $24 \%$ of severely injured patients had acute traumatic coagulopathy on the hospital arrival [3]. Recent evidence suggests that coagulopathy should be thought of as a primary event, which

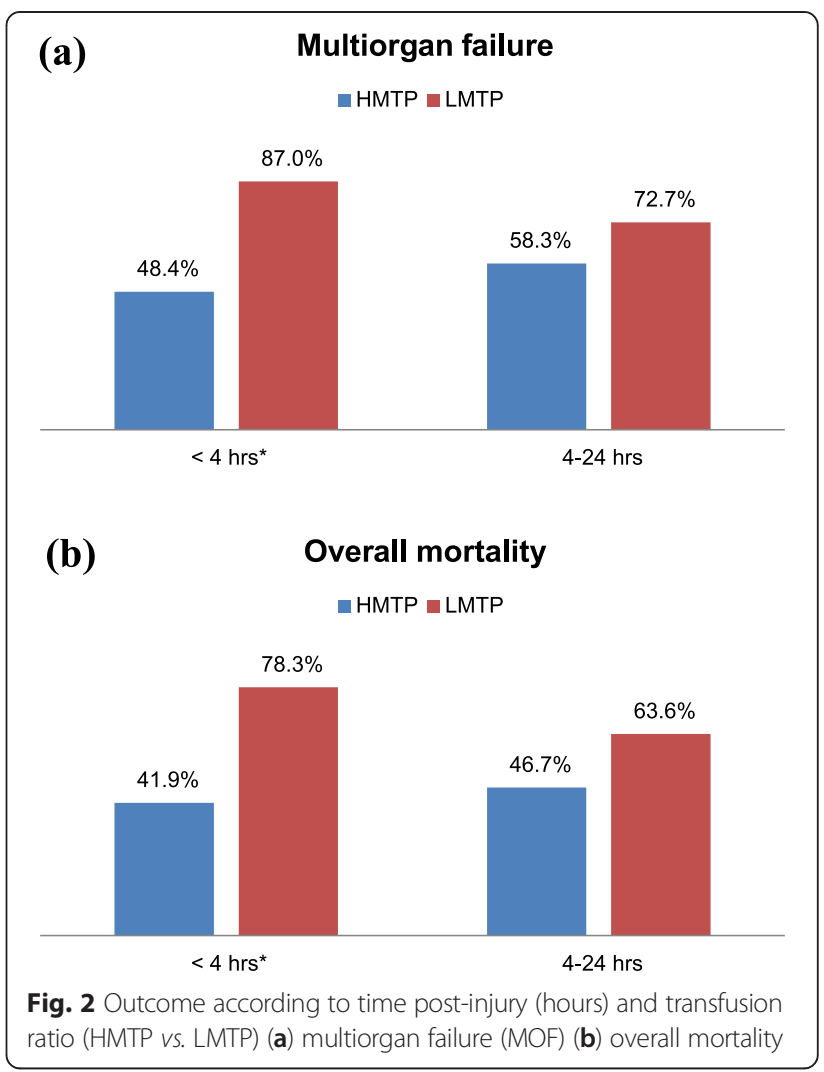

is independently associated with detrimental outcomes. Therefore, more attention has been given to control the worse outcomes of acute traumatic coagulopathy through hemostatic resuscitation which improves patient outcomes [13]. Particularly, the role of FFP in managing traumatic coagulopathy is well documented. Despite the fact that use of high transfusion ratios is still a debatable issue, the majority of studies supported early and aggressive plasma use to attain FFP: PRBC transfusion ratios as high as 1:1 [4, 14, 15]. However, in the current practice there is no consensus on the optimal cut-off between adequately high and low plasma to PRBC ratios. Table 4 presents a comparison of several studies with respect to different FFP: PRBC cut-off ratios, timing and outcomes $[4,5,14-24]$.

Our study revealed a significant improvement in the crude mortality and MOF rate when a FFP: PRBC transfusion ratio $\geq 1: 1.5$ was attainable within the initial $4 \mathrm{~h}$ of admission. As it have been shown in Fig. 3; the number of deaths within the first 30 days was 3 times higher in LMTP group and most deaths occurred within the first $24 \mathrm{~h}$ and particularly within the first $6 \mathrm{~h}$ in the 2 study groups.

Comparable survival benefit was documented in other studies that have used similar high transfusion ratios at different time durations [14-16]. However, achievement of such ratio as early as in the first $4 \mathrm{~h}$ and its impact 


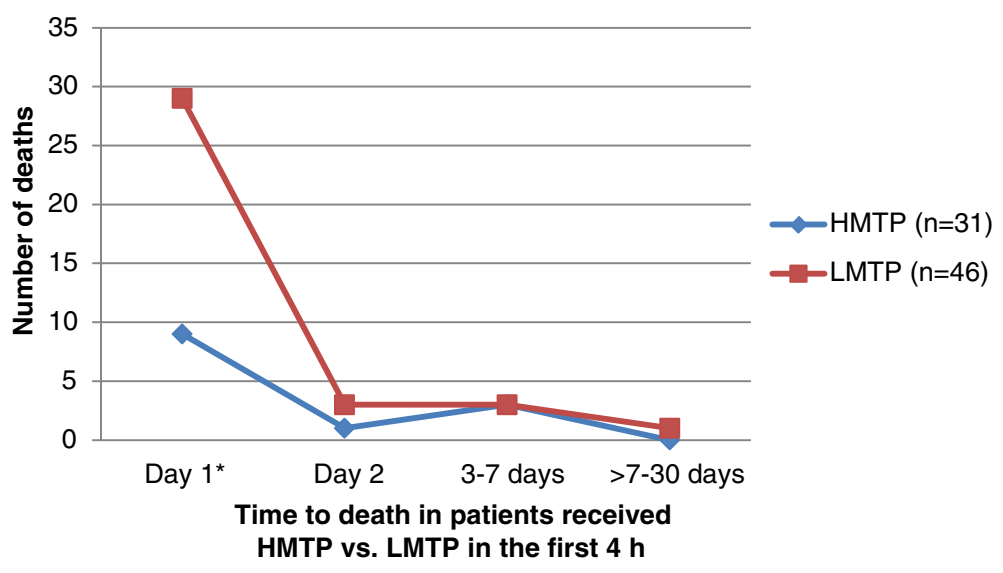

Fig. 3 Number and time of hospital death in patients who received HMTP vs. LMTP in the first $4 \mathrm{~h}$

on patient outcome has been described recently by Mitra et al. [19]. Consistent with our findings, the authors reported survival benefit for higher FFP: PRBC ratios during the first $4 \mathrm{~h}$ of resuscitation in severely injured blunt trauma patients. Moreover, the low FFP: PRBC ratio during the early phase was independently associated with the risk of mortality.

Of note, the improvement in mortality and MOF rates with high transfusion ratios were observed only during the early period of hemostatic resuscitation and were not seen later on $(>4-24 \mathrm{~h})$ in our study. Hence, we believe that the survival benefit observed in other studies when the ratios were calculated at $24 \mathrm{~h}$ is possibly a dilution effect.

Snyder et al. [17] introduced the question of survival bias for transfusion ratio in massively transfused trauma patients. The authors observed a significant association between improved survival and high transfusion ratios during the first $24 \mathrm{~h}$. But this relationship did not sustain after adjustment for survival bias in the study cohort.

Similarly, Teixeira et al. [18] conducted a 6-year retrospective study to analyze the effect of plasma transfusion $(\geq 10$ PRBC) among massively transfused patients and observed a survival benefit for higher FFP: PRBC ratio during initial 24 h. De Baisi et al. [25] reported that mortality was significantly correlated with worse plasma deficit during the initial $2 \mathrm{~h}$ of resuscitation but no association with plasma ratio was reported. A similar association was observed among the massive transfusion group at $24 \mathrm{~h}$.

Several studies have shown a correlation between FFP transfusion and the development of hospital complications. Khan et al. [26] suggested that FFP transfusion is independently associated with the risk of acute lung injury and acute respiratory distress syndrome (ARDS). In addition, Sperry et al. [5] observed 2 times higher risk of ARDS in patients resuscitated with a high FFP: PRBC ratio. In contrast, our study reported a lower MOF rate among the high ratio group within the early as well as late phase. Both groups were comparable in terms of the initial coagulopathy, injury severity and demographic status except for age. We also noted progressive improvement in the coagulopathy status in the high ratio group. These results substantiate our current understandings of the utility of aggressive plasma use to prevent and treat early onset coagulopathy after injury. Furthermore, the rate of nosocomial infections did not reach statistical significance in either group. However, high ratio group patients had higher rates of wound infection and pneumonia which might explain the potential complications and risks attributable to this type of resuscitative practice.

Our study has some limitations including its retrospective nature. Being a single institution study, we are limited with the small sample size and power in addition to the lack of detailed description of the coagulation management. We were also not able to account for the incidence of ARDS. Also, the possibility of survival bias and incompleteness of collected data cannot be ruled out. We were looking for the MTP and the death burden from exsanguination, not the over-all death burden. After all, an MTP's main objective is to reduce deaths from traumatic hemorrhage. All deaths due to the severity of injury were 'pre-ordained' already. To date most of the studies have calculated FFP: PRBC ratios at $24 \mathrm{~h}$. Therefore, analysis of ratios at $4 \mathrm{~h}$ would help to counter survival bias to some extent [19]. The proper ratios and time for administrating MTP in trauma patients are not well defined yet in the literatures (Table 4). In our institute, the MTP protocol was fully implemented in 2011 and so the difference in transfusion practice can be attributed to practice variation as well as the 'learning curve' that attends the implementation of any new clinical protocol. Furthermore the data were collected retrospectively so we cannot assume the 
Table 4 Review of massive transfusion studies

\begin{tabular}{|c|c|c|c|c|c|c|}
\hline Reference & $\begin{array}{l}\mathrm{N} \text { of } \\
\text { pts }\end{array}$ & Mechanism & $\begin{array}{l}\text { Massive transfusion } \\
\text { definition }\end{array}$ & $\begin{array}{l}\text { Time ratio } \\
\text { calculated }\end{array}$ & Plasma : PRBC ratio & Results \\
\hline \multirow{3}{*}{$\begin{array}{l}\text { Borgman et al., } \\
2007[4]\end{array}$} & \multirow[t]{3}{*}{246} & \multirow{3}{*}{$\begin{array}{l}94 \% \\
\text { penetrating } \\
\text { (military) }\end{array}$} & \multirow{3}{*}{$\begin{array}{l}\geq 9 \cup R B C \text { in } 1 s t \\
24 \mathrm{~h}\end{array}$} & \multirow[t]{3}{*}{$24 \mathrm{~h}$} & Low: 1:8, & \multirow{3}{*}{$\begin{array}{l}\text { Overall Mortality in low }-65 \% \text {, medium-34\%, } \\
\text { high-19\%, }(P<.001) \text {. }\end{array}$} \\
\hline & & & & & Medium: 1:2.5 & \\
\hline & & & & & High:1:1.4 & \\
\hline \multirow{2}{*}{$\begin{array}{l}\text { Sperry et al., } \\
2008[5]\end{array}$} & \multirow[t]{2}{*}{415} & \multirow[t]{2}{*}{$100 \%$ blunt } & \multirow{2}{*}{$\begin{array}{l}\geq 8 \cup \mathrm{RBC} \text { in } 1 \mathrm{st} \\
8 \mathrm{~h}\end{array}$} & \multirow[t]{2}{*}{$12 \mathrm{~h}$} & Low: $<1: 1.5$ & \multirow{2}{*}{$\begin{array}{l}\text { 24-h mortality in low-12.8\%, high - 3.9\% }(P=0.012) \text {. } \\
\text { Benefit gone by } 48 \mathrm{~h}\end{array}$} \\
\hline & & & & & High: $\geq 1: 1.5$ & \\
\hline \multirow{2}{*}{$\begin{array}{l}\text { Holcomb et al., } \\
2008[14]\end{array}$} & \multirow[t]{2}{*}{466} & \multirow{2}{*}{$\begin{array}{l}35 \% \\
\text { penetrating }\end{array}$} & \multirow{2}{*}{$\begin{array}{l}\geq 9 \cup R B C \text { in } 1 s t \\
24 \mathrm{~h}\end{array}$} & \multirow[t]{2}{*}{$24 \mathrm{~h}$} & Low: $<1: 2$ & \multirow{2}{*}{$\begin{array}{l}\text { Improved 30-day survival in high ratio (59.6 vs. } 40.4 \% \text {; } \\
P<0.01 \text { ) }\end{array}$} \\
\hline & & & & & High: $\geq 1: 2$ & \\
\hline \multirow{2}{*}{$\begin{array}{l}\text { Gunter et al. } \\
2008 \text { (15) }\end{array}$} & \multirow[t]{2}{*}{259} & \multirow{2}{*}{$\begin{array}{l}55 \% \\
\text { penetrating }\end{array}$} & \multirow{2}{*}{$\begin{array}{l}\geq 10 \cup \mathrm{RBC} \text { in } 1 \mathrm{st} \\
24 \mathrm{~h}\end{array}$} & \multirow[t]{2}{*}{$24 \mathrm{~h}$} & Low: $<1: 1.5$ & \multirow{2}{*}{$\begin{array}{l}\text { reduction in 30-day mortality: high ( } 41 \% \text { ) vs. low (62 \%) } \\
\text { ratio group } p=0.008\end{array}$} \\
\hline & & & & & High: $\geq 1: 1.5$ & \\
\hline \multirow[t]{3}{*}{$\begin{array}{l}\text { Maegele et al., } \\
2008 \text { [16] }\end{array}$} & \multirow[t]{3}{*}{713} & \multirow[t]{3}{*}{$92 \%$ blunt } & \multirow[t]{3}{*}{$\begin{array}{l}\geq 10 \cup \mathrm{RBC} E \mathrm{ED} \rightarrow \\
\mathrm{ICU} \text { admission }\end{array}$} & \multirow[t]{3}{*}{ NA } & $\begin{array}{l}\text { PRBC:FFP > 1.1, } \\
\text { PRBC:FFP 0.9-1.1 }\end{array}$ & 6 h mortality $24.6,9.6 \& 3.5 \%(P<0.0001)$ \\
\hline & & & & & PRBC:FFP $<0.9$ & 24 h mortality 32.6, $16.7 \& 11.3 \%(P<0.0001)$ \\
\hline & & & & & & 30 day mortality $45.5,35.1 \& 24 \%(P<0.001)$ \\
\hline Snyder et al., & 134 & $60 \%$ & $\geq 10 \cup \mathrm{RBC}$ in $1 \mathrm{st}$ & $24 \mathrm{~h}$ & Low: $<1: 2$ & 24-h mortality in low-58\%, High - $40 \%$; but effect \\
\hline 2009 [1/] & & penetrating & & & High: $\geq 1: 2$ & disappears when analyzed as time \\
\hline Teixeira et al., & 383 & NA & $\geq 10 \cup \mathrm{RBC}$ in $1 \mathrm{st}$ & $24 \mathrm{~h}$ & Low: $\leq 1: 8$ & Mortality rate decreased significantly with increased \\
\hline & & & & & $\begin{array}{l}\text { Medium: }>1: 8 \& \\
\leq 1: 3\end{array}$ & \\
\hline & & & & & High: $>1: 3 \& \leq 1: 2$ & \\
\hline Mitra et al., & 331 & $86 \%$ blunt & $\geq 5 \cup R B C$ in $1 s t$ & $4 \mathrm{~h}$ & $>1: 1.5$ & higher ratios were associated with significantly improved \\
\hline & & & & & $>1: 2.5$ to $1: 1.5$ & \\
\hline & & & & & $>1: 3.5$ to $1: 2.5$ & \\
\hline & & & & & $\leq 1: 3.5$ & \\
\hline Magnotti et al., & 103 & $63 \%$ blunt & $\geq 10 \cup \mathrm{RBC}$ in $1 \mathrm{st}$ & $6 \mathrm{~h}$ & Low: $<1: 2$ & 6 -h mortality was less in the high-group ( $10 \%$ vs. $48 \%$, \\
\hline & & & & & High: $\geq 1: 2$ & \\
\hline Lustenberger & 229 & $100 \%$ blunt & $\geq 10 \cup \mathrm{RBC}$ in $1 \mathrm{st}$ & $12,24 \mathrm{~h}$ & Low: $<1: 1.5$ & High ratio was associated with improved survival at 12 \\
\hline & & & & & High: $\geq 1: 1.5$ & \\
\hline Brown et al., & 604 & $100 \%$ blunt & $\geq 10 \cup R B C$ in $1 s t$ & 6,12, & Low: $<1: 1.5$ & High 6-h ratios were associated with a reduction in \\
\hline & & & & & High: $\geq 1: 1.5$ & \\
\hline Kudo et al., & NA & NA & $\geq 10 \cup R B C$ in 1 st & $6 \mathrm{~h}$ & High: >1:1.5, & Mortality rate: high (44.4\%); \\
\hline & & & & & Medium: 1:1.5-1:2 & Middle (16.7 \%); low (33.3 \%) \\
\hline & & & & & Low: $<1: 2$ & \\
\hline $\begin{array}{l}\text { Holcomb et al., } \\
2015[24]\end{array}$ & 680 & $\begin{array}{l}\text { Severely injured } \\
\text { (55\% blunt) }\end{array}$ & $\begin{array}{l}\geq 10 \cup \text { of RBCs } \\
\text { within } 24 \mathrm{~h}\end{array}$ & $6 \mathrm{~h}$ & $\begin{array}{l}1: 1: 1 \text { transfusion } \\
\text { ratio of plasma, } \\
\text { platelets, and } \mathrm{RBCs} \\
\text { to a } 1: 1: 2 \text { ratio }\end{array}$ & $\begin{array}{l}\text { early administration of plasma, platelets, and red blood } \\
\text { cells in a 1:1:1 ratio compared with a 1:1:2 ratio did not } \\
\text { result in significant differences in mortality at } 24 \mathrm{~h} \text { or at } \\
30 \text { days }\end{array}$ \\
\hline Present study & 77 & $88.3 \%$ Blunt & $\geq 10 \cup \mathrm{RBC}$ in $1 \mathrm{st}$ & $4 \mathrm{~h}$ & Low: $<1: 1.5$ & higher ratios were significantly associated with lower \\
\hline & & $\begin{array}{l}11.7 \% \\
\text { penetrating }\end{array}$ & & & High: $\geq 1: 1.5$ & \\
\hline
\end{tabular}

exact reason behind this time and ratio variations except for physician discretion in the absence of hospital protocol at that time. Lastly, multi-year retrospective studies might suffer from the same 'potential bias' that could be encountered in our analysis.

\section{Conclusions}

The mortality risk associated with low FFP: PRBC ratios of $<1: 1.5$ may occur very early, possibly secondary to ongoing coagulopathy and hemorrhage. Aggressive attainment of high FFP/PRBC ratios as early as $4 \mathrm{~h}$ post injury can 
substantially improve coagulopathy and reduce mortality and MOF rates. The present study is an audit of massive transfusion strategies used at our center which highlights the current experience of managing exsanguinating trauma patients. The analysis of appropriate transfusion ratios and timings provides useful information regarding the correct ratios of blood component and avoiding wastage of the blood products. This information can form the basis for developing research based uniform massive transfusion guidelines for the appropriate use of various blood components. Furthermore, it can be the basis for designing massive transfusion research focusing high transfusion ratios targeted within the first $4 \mathrm{~h}$. Therefore, large prospective studies are needed to validate our findings for a balanced FFP: PRBC ratio that would decrease the overall PRBC utilization and the decision needed for massive transfusion.

\section{Abbreviations}

MTP: Massive transfusion protocol; MOF: multiorgan failure; FFP: fresh frozen plasma; PRBC: Packed red blood cells; ISS: Injury Severity Score; RTS: Revised Trauma Score; HMTP: high MTP; LMTP: low MTP; INR: International Normalized Ratio; VAP: Ventilator associated pneumonia; BSI: blood stream infection; CRBSI: Catheter-related blood stream infections; UTI: Urinary tract infection.

\section{Competing interests}

The author(s) declare that they have no competing interests.

\begin{abstract}
Authors' contributions
RP: study design data interpretation, and manuscript drafting; AV: study design data interpretation, and manuscript drafting; AE: data analysis and interpretation, drafting and manuscript review; RC: study design data interpretation, and manuscript drafting; HA: data analysis, interpretation, and drafting; AP: was involved in study design, data collection and writing manuscript; IA: was involved in study design, data collection and writing manuscript; AZ: data analysis, interpretation, and drafting, HA: study design, data interpretation, and review manuscript, AP: study design data interpretation, and manuscript review; and RL: study design data interpretation, and manuscript review. All authors read and approved the final manuscript.
\end{abstract}

\section{Authors' information}

RP: Trauma Surgery Section, Hamad General Hospital, Qatar; AV: Trauma Surgery Section, Hamad General Hospital, Qatar; AE: Clinical Research, Trauma Surgery Section, Hamad General Hospital, Qatar and Weill Cornell Medical School, Doha, Qatar; RC: Trauma Surgery Section, Hamad General Hospital, Qatar; HA: Trauma Surgery Section, Hamad General Hospital, Qatar; AP: Trauma Surgery Section, Hamad General Hospital, Qatar; IA: Trauma Surgery Section, Hamad General Hospital, Qatar; AZ: Trauma Surgery Section, Hamad General Hospital, Qatar; HA: Trauma Surgery Section, Hamad General Hospital, Qatar; RL: Trauma Surgery Section, Hamad General Hospital, Qatar and Department of Surgery, Arizona University, Tucson, AZ, USA.

\section{Acknowledgement}

We thank the entire registry database team in the section of trauma surgery. All authors read the manuscript and approved it and had no financial issues to disclose. Medical Research Center (IRB\# 11153/11) at Hamad Medical Corporation, Qatar has approved the study.

This study has been presented in part at the 43rd Annual Congress of the Society of Critical Care Medicine, San Francisco, California, USA.

\section{Author details}

${ }^{1}$ Trauma Surgery Section, Hamad Trauma Center, Hamad General Hospital, Doha, Qatar. ${ }^{2}$ Clinical Research, Trauma Surgery Section, Hamad General Hospital, HMC, PO Box 3050, Doha, Qatar. ${ }^{3}$ Clinical Medicine, Weill Cornell Medical College, Doha, Qatar. ${ }^{4}$ Department of Surgery, University of Arizona, Tucson, AZ, USA.
Received: 24 March 2015 Accepted: 23 July 2015

Published online: 14 August 2015

\section{References}

1. Peng R, Chang C, Gilmore D, Bongard F. Epidemiology of immediate and early trauma deaths at an urban Level I trauma center. Am Surg. 1998;64:950-4.

2. Demetriades D, Murray J, Charalambides K, Alo K, Velmahos G, Rhee P, et al. Trauma fatalities: time and location of hospital deaths. J Am Coll Surg. 2004;198:20-6.

3. Brohi K, Singh J, Heron M, Coats T. Acute traumatic coagulopathy. J Trauma. 2003;54:1127-30

4. Borgman MA, Spinella PC, Perkins JG, Grathwohl KW, Repine T, Beekley AC, et al. The ratio of blood products transfused affects mortality in patients receiving massive transfusions at a combat support hospital. J Trauma. 2007:63:805-13.

5. Sperry JL, Ochoa JB, Gunn SR, Alarcon LH, Minei JP, Cuschieri J, et al. Inflammation the Host Response to Injury Investigators: An FFP:PRBC transfusion ratio $>/=1: 1.5$ is associated with a lower risk of mortality after massive transfusion. J Trauma. 2008;65:986-93.

6. Gajic O, Dzik WH, Toy P. Fresh frozen plasma and platelet transfusion for non-bleeding patients in the intensive care unit: benefit or harm? Crit Care Med. 2006;34 Suppl 5:170-3.

7. MacLennan S, Williamson LM. Risks of fresh frozen plasma and platelets. J Trauma. 2006;60 Suppl 6:46-50.

8. Silliman CC, Ambruso DR, Boshkov LK. Transfusion-related acute lung injury. Blood. 2005;105:2266-73.

9. Dutton RP. Resuscitative strategies to maintain homeostasis during damage control surgery. Br J Surg. 2012;99 Suppl 1:21-8.

10. Meißner A, Schlenke P. Massive Bleeding and Massive Transfusion. Transfus Med Hemother. 2012;39:73-84.

11. Minei JP, Nathens AB, West M, Harbrecht BG, Moore EE, Shapiro MB, et al. Inflammation and the Host Response to Injury Large Scale Collaborative Research Program Investigators. Inflammation and the Host Response to Injury, a Large-Scale Collaborative Project: patient-oriented research core-standard operating procedures for clinical care. II. Guidelines for prevention, diagnosis and treatment of ventilator-associated pneumonia (VAP) in the trauma patient. J Trauma. 2006;60:1106-13.

12. Kashuk JL, Moore EE, Millikan JS, Moore JB. Major abdominal vascular trauma - a unified approach. J Trauma. 1982;22:672-9.

13. Kautza BC, Cohen MJ, Cuschieri J, Minei JP, Brackenridge SC, Maier RV, et al. Inflammation and the Host Response to Injury Investigators: Changes in massive transfusion over time: an early shift in the right direction? I Trauma Acute Care Surg. 2012;72:106-11.

14. Holcomb JB, Wade CE, Michalek JE, Chisholm GB, Zarzabal LA, Schreiber MA, et al. Increased plasma and platelet to red blood cell ratios improves outcome in 466 massively transfused civilian trauma patients. Ann Surg. 2008;248:447-58

15. Gunter Jr OL, Au BK, Isbell JM, Mowery NT, Young PP, Cotton BA. Optimizing outcomes in damage control resuscitation: identifying blood product ratios associated with improved survival. J Trauma. 2008;65:527-34.

16. Maegele M, Lefering R, Paffrath T, Tjardes T, Simanski C, Bouillon B. Working Group on Polytrauma of the German Society of Trauma Surgery (DGU). Red-blood-cell to plasma ratios transfused during massive transfusion are associated with mortality in severe multiple injury: a retrospective analysis from the Trauma Registry of the Deutsche Gesellschaft für Unfallchirurgie. Vox Sang. 2008;95:112-19.

17. Snyder CW, Weinberg JA, McGwin Jr G, Melton SM, George RL, Reiff DA, et al. The relationship of blood product ratio to mortality: Survival benefit or survival bias? J Trauma. 2009;66:358-62.

18. Teixeira PG, Inaba K, Shulman I, Salim A, Demetriades D, Brown C, et al. Impact of plasma transfusion in massively transfused trauma patients. J Trauma. 2009;66:693-7.

19. Mitra B, Mori A, Cameron PA, Fitzgerald M, Paul E, Street A. Fresh frozen plasma (FFP) use during massive blood transfusion in trauma resuscitation. Injury. 2010;41:35-9.

20. Magnotti LJ, Zarzaur BL, Fischer PE, Williams RF, Myers AL, Bradburn EH, et al. Improved survival after hemostatic resuscitation: does the emperor have no clothes? J Trauma. 2011;70:97-102.

21. Lustenberger T, Frischknecht A, Brüesch M, Keel MJ. Blood component ratios in massively transfused blunt trauma patients a time-dependent covariate analysis. J Trauma. 2011;71:1144-50. 
22. Brown JB, Cohen MJ, Minei JP, Maier RV, West MA, Billiar TR, et al. Inflammation and Host Response to Injury Investigators: Debunking the survival bias myth: characterization of mortality during the initial $24 \mathrm{~h}$ for patients requiring massive transfusion. J Trauma Acute Care Surg. 2012;73:358-64.

23. Kudo D, Sasaki J, Akaishi S, Yamanouchi S, Koakutsu T, Endo T, et al. Efficacy of a high FFP:PRBC transfusion ratio on the survival of severely injured patients: a retrospective study in a single tertiary emergency center in Japan. Surg Today. 2014;44:653-61.

24. Holcomb JB, Tilley BC, Baraniuk S, Fox EE, Wade CE, Podbielski JM, et al. Transfusion of plasma, platelets, and red blood cells in a 1:1:1 vs a 1:1:2 ratio and mortality in patients with severe trauma: the PROPPR randomized clinical trial. JAMA. 2015;313(5):471-82.

25. de Biasi AR, Stansbury LG, Dutton RP, Stein DM, Scalea TM, Hess JR. Blood product use in trauma resuscitation: plasma deficit versus plasma ratio as predictors of mortality in trauma (CME). Transfusion. 2011;51:1925-32.

26. Khan H, Belsher J, Yilmaz M, Afessa B, Winters JL, Moore SB, et al. Fresh-frozen plasma and platelet transfusions are associated with development of acute lung injury in critically ill medical patients. Chest. 2007;131:1308-14.

\section{Submit your next manuscript to BioMed Central and take full advantage of:}

- Convenient online submission

- Thorough peer review

- No space constraints or color figure charges

- Immediate publication on acceptance

- Inclusion in PubMed, CAS, Scopus and Google Scholar

- Research which is freely available for redistribution 